\title{
Pyrophosphate-Dependent Enzymes in Walled Bacteria Phylogenetically Related to the Wall-Less Bacteria of the Class Mollicutes $\dagger$
}

\author{
JAMES P. PETZEL, ${ }^{1} \ddagger$ PAUL A. HARTMAN, ${ }^{1 *}$ AND MILTON J. ALLISON ${ }^{2}$ \\ Department of Microbiology, Iowa State University, Ames, Iowa 50011-3211, ${ }^{1}$ and National Animal Disease Center, \\ U.S. Department of Agriculture, Ames, Iowa $50010^{2}$
}

\begin{abstract}
Some of the wall-less bacteria of the class Mollicutes (mycoplasmas) have pyrophosphate $\left(\mathbf{P P}_{\mathrm{i}}\right)$-dependent

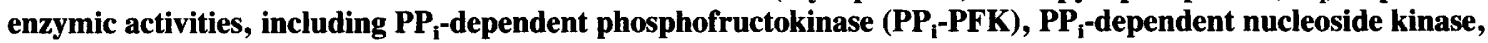
and pyruvate,orthophosphate dikinase (PPDK) activities. In most other bacteria, adenosine $5^{\prime}$-triphosphate (ATP), not $\mathbf{P P}_{\mathrm{i}}$, is the cofactor of analogous enzymic reactions. Because $\mathbf{P P}_{\mathrm{i}}$-dependent enzymes are more common among mollicutes than other bacteria, we describe here an examination of the six walled bacteria that have been reported to be phylogenetically related to the mollicutes (Clostridium innocuum, Clostridium ramosum, Erysipelothrix rhusiopathiae, Lactobacillus catenaformis, Lactobacillus vitulinus, and Streptococcus pleomorphus) for PP $_{\mathrm{i}}$-PFK, ATP-dependent PFK, phosphoenolpyruvate carboxytransphosphorylase, PPDK, and $\mathbf{P P}_{\mathrm{i}^{-}}$and $\mathbf{A T P}$-dependent acetate kinases. Two anaerobic mollicutes, Anaeroplasma intermedium and Asteroleplasma anaerobium, were also tested. C. innocuum, E. rhusiopathiae, S. pleomorphus, and Anaeroplasma intermedium had $\mathrm{PP}_{\mathrm{i}}$-PFK activities, whereas $C$. ramosum, the two lactobacilli, and Asteroleplasma anaerobium had only ATP-dependent PFK activities. Asteroleplasma anaerobium and all of the walled bacteria except $E$. rhusiopathiae had PPDK activities. All of the species except Asteroleplasma anaerobium and $E$. rhusiopathiae also had pyruvate kinase activities; the effects of allosteric activators were tested. Phosphoenolpyruvate carboxytransphosphorylase was detected by using two methods in $C$. innocuum, $C$. ramosum, and $S$. pleomorphus. All of the species tested had ATP-dependent acetate kinase activities, but none had detectable $\mathbf{P P}_{\mathrm{i}}$-dependent acetate kinase activity. The occurrence of one or more $\mathrm{PP}_{\mathrm{i}}$-dependent enzymes in the mollicutes and their walled relatives is a phenotypic indicator of the phylogenetic relatedness of these organisms. The distribution of these enzymes among members of this group substantiates the subgroups proposed by other workers who used $16 \mathrm{~S}$ ribosomal ribonucleic acid analysis.
\end{abstract}

The wall-less eubacteria belonging to the genera $M y c o-$ plasma, Ureaplasma, Spiroplasma, Acholeplasma, Anaeroplasma, and Asteroleplasma are grouped together in the class Mollicutes. Phylogenetic analyses of 5S and 16S ribosomal ribonucleic acid (rRNA) sequences have revealed that the mollicutes cluster with the low-guanine-plus-cytosine content subdivision of gram-positive eubacteria that includes the bacillus-lactobacillus-streptococcus branch $(31,40,41)$. Among the members of the low-guanine-plus-cytosine content gram-positive eubacteria, the mollicutes are most closely related to Clostridium innocuum, Clostridium ramosum, Erysipelothrix rhusiopathiae, Lactobacillus catenaformis (Lactobacillus catenaforme), Lactobacillus vitulinus, and Streptococcus pleomorphus $(16,31,40-42 ; \mathrm{W}$. G. Weisburg, J. G. Tully, D. L. Rose, J. P. Petzel, H. Oyaizu, D. Yang, L. Mandelco, J. Sechrest, T. G. Lawrence, J. Van Etten, J. Maniloff, and C. R. Woese, submitted for publication).

The mollicutes and their walled phylogenetic relatives have few phenotypic similarities. The only comparative study of the phenotypes of the mollicutes and their walled phylogenetic relatives was conducted by Pellegrin et al. (J. L. Pellegrin, J. Maugein, M. Clerc, B. Leng, and C. Bebear, Abstr. 7th Congr. Int. Organ. Mycoplasmol., abstr.

\footnotetext{
* Corresponding author.

$\uparrow$ Dedicated to Isadore M. Robinson. Journal Paper J-13458 of the Iowa Agriculture and Home Economics Experiment Station, Ames (project 2678).

$\ddagger$ Present address: Department of Food Science and Nutrition, University of Minnesota, Saint Paul, MN 55108.
}

no. $\mathrm{P} 114,1988)$. These authors found that Clostridium innocuum, Clostridium ramosum, and six species of mollicutes (belonging to four genera) were all resistant to high levels of rifampin. Generally, eubacteria are susceptible to rifampin, an inhibitor of ribonucleic acid polymerase; some mollicutes, however, are resistant (10).

Some members of the orders Mycoplasmatales and Acholeplasmatales have activities for (deoxy)ribonucleoside kinases that are dependent on pyrophosphate $\left(\mathrm{PP}_{\mathrm{i}}\right)$ as a cofactor $(18,38)$, and Acholeplasma spp. have $\mathrm{PP}_{\mathrm{i}}$-dependent 6-phosphofructokinase ( $\mathrm{PP}_{\mathrm{i}}$-PFK) activity $(7,23)$. Among the anaerobic mollicutes, both Anaeroplasma intermedium (18) and Asteroleplasma anaerobium (J. P. Petzel, M. C. McElwain, D. DeSantis, J. Manolukas, M. V. Williams, P. A. Hartman, M. J. Allison, and J. D. Pollack, Arch. Microbiol., in press) have activities for $\mathbf{P P}_{\mathrm{i}}$-dependent nucleoside kinases. Anaeroplasma intermedium also has $\mathrm{PP}_{\mathrm{i}}$-PFK activity, whereas Asteroleplasma anaerobium has activity for a third $\mathrm{PP}_{\mathrm{i}}$-dependent enzyme, pyruvate,orthophosphate dikinase (PPDK; Petzel et al., in press). PP $_{\mathrm{i}^{-}}$ dependent nucleoside kinase has not been reported in any organism other than some mollicutes $(18,22,38)$. Adenosine 5 '-triphosphate (ATP) serves as the phosphate donor in the phosphofructokinase (PFK) reaction instead of $P P_{i}$ in the great majority of bacteria. PPDK, which converts phosphoenolpyruvate (PEP) to pyruvate, has been reported in only a few procaryotes (43).

Because $\mathrm{PP}_{\mathrm{i}}$-dependent enzymes are generally rare among procaryotes but occur more frequently among the mollicutes, and because $\mathrm{PP}_{\mathrm{i}}$ may be an evolutionary precursor of ATP $(14,43)$, we examined the walled phylogenetic relatives 
of the mollicutes and some members of the family Anaeroplasmataceae for the following four $\mathrm{PP}_{\mathrm{i}}$-dependent enzymes: PP $_{\mathrm{i}}$-PFK, PPDK, PEP carboxytransphosphorylase, and $\mathrm{PP}_{\mathrm{i}}$-dependent acetate kinase. We also assayed these bacteria for some analogous ATP-dependent enzyme activities.

\section{MATERIALS AND METHODS}

Strains. Clostridium innocuum ATCC $14501^{\mathrm{T}}$ ( $\mathrm{T}=$ type strain), Lactobacillus catenaformis ATCC $25536^{\mathrm{T}}$ (= DSM $20559^{\mathrm{T}}$ ), Lactobacillus vitulinus ATCC $27783^{\mathrm{T}}$, and Streptococcus pleomorphus ATCC $29734^{\mathrm{T}}$ (= DSM 20574 ${ }^{\mathrm{T}}$ ) were obtained from the American Type Culture Collection, Rockville, Md. Anaeroplasma intermedium 5LA and $7 \mathrm{LA}^{\mathrm{T}}$ (= ATCC $\left.43166^{\mathrm{T}}\right)(28,30)$ and Asteroleplasma anaerobium $161^{\mathrm{T}}$ (= ATCC 27880 ${ }^{\mathrm{T}}$ ) (30) were obtained from I. M. Robinson, National Animal Disease Center, U.S. Department of Agriculture, Ames, Iowa. Erysipelothrix rhusiopathiae AVR-9 was obtained from R. L. Wood, National Animal Disease Center. Clostridium innocuum 7207 and Clostridium ramosum 8546 were received from the Anaerobe Laboratory, Virginia Polytechnic Institute and State University, Blacksburg.

Cultivation and extract preparation. The mollicutes were harvested from 1.2 liters of $\mathrm{S}-2$ broth ( $\leq 0.5 \%$ inocula; incubation for 4 to 6 days at $37^{\circ} \mathrm{C}$ ) as described elsewhere (Petzel et al., in press). Erysipelothrix rhusiopathiae was grown $\left(0.8 \%\right.$ inoculum; incubation for 2 days at $\left.37^{\circ} \mathrm{C}\right)$ in 1.2 liters of S-2 broth with the following modifications: the medium was supplemented with $1.7 \%(\mathrm{vol} / \mathrm{vol})$ heat-inactivated horse serum and $10 \mathrm{mM}$ MES [2- $(N$-morpholino)ethanesulfonic acid]; the lipids and $\mathrm{Na}_{2} \mathrm{CO}_{3}$ were deleted, and the culture was incubated without anaerobic precautions. All other species were grown in $800 \mathrm{ml}$ of $\mathrm{S}-2$ broth without the lipids $\left(0.25 \%\right.$ inocula; incubation for 20 to $22 \mathrm{~h}$ at $\left.37^{\circ} \mathrm{C}\right)$.

Extracts of the mollicutes were prepared by osmotic lysis (Petzel et al., in press). Pellets of walled bacteria were suspended in the same lysis buffer and were passed through a French pressure cell two to four times. Lysates were clarified by centrifugation at $8,800 \times g_{\max }$ and $4^{\circ} \mathrm{C}$ for $15 \mathrm{~min}$ and then at $230,000 \times g_{\max }$ and $4^{\circ} \mathrm{C}$ for $1 \mathrm{~h}$ unless noted otherwise. Samples of the cell-free extracts were either frozen at $-75^{\circ} \mathrm{C}$ or dialyzed against 100 volumes of lysis buffer $\left(20 \mathrm{~h}, 4^{\circ} \mathrm{C}\right.$, one change) before being frozen. Some cell-free extracts were frozen under argon; no differences in activity were observed between these preparations and those with which no anaerobic precautions were taken. Protein concentrations were determined by using the BCA protein assay reagent (Pierce Chemical Co., Rockford, Ill.) and bovine serum albumin as the standard.

Enzyme assays. Biochemicals were obtained from Sigma Chemical Co., St. Louis, Mo. All potentially labile substrates and cofactors were prepared in buffers and stored in the manner appropriate for maximum stability (2). ATP was determined by the method of Trautschold et al. (37).

ATP-dependent 6-phosphofructokinase (ATP-PFK) (EC 2.7.1.11) and $P P_{i}-P F K$ (EC 2.7.1.90) were assayed in the forward direction by method $\mathrm{B}$ of O'Brien et al. (21). $\mathrm{PP}_{\mathrm{i}}$-PFK was also assayed in the reverse direction by method A (21). PPDK (EC 2.7.9.1) was assayed by determining the appearance of ATP (8) $\left[\left(\mathrm{NH}_{4}\right)_{6} \mathrm{Mo}_{7} \mathrm{O}_{24}\right.$ was omitted] and by determining the appearance of pyruvate (9) (the concentration of $\mathrm{MgCl}_{2}$ was decreased to $7.4 \mathrm{mM}$ ). PEP carboxytransphosphorylase (EC 4.1.1.38) was assayed by following the appearance of oxaloacetate, using a modifica- tion of the method of Wood et al. (44). The mixture of $\mathrm{KHCO}_{3}, \mathrm{MgCl}_{2}$, and potassium phosphate buffer in a serum bottle was sparged with $\mathrm{CO}_{2}$ for $30 \mathrm{~min}$, the bottle was sealed with a septum, and samples were withdrawn with a syringe as needed. In addition, the concentration of $\mathrm{CoCl}_{2}$ was reduced to $10 \mu \mathrm{M}$, and dithiothreitol was substituted for $\beta$-mercaptoethanol. PEP carboxytransphosphorylase was also assayed by determining the appearance of $\mathrm{PP}_{i}$; the assay mixture used for the oxaloacetate assay was modified by deleting reduced nicotinamide adenine dinucleotide and malate dehydrogenase and increasing the concentration of $\mathrm{CoCl}_{2}$ to $100 \mu \mathrm{M}$. The reaction mixtures were incubated under $\mathrm{CO}_{2}$ for $30 \mathrm{~min}$ at $37^{\circ} \mathrm{C}$; mixtures without PEP served as controls. $\mathrm{PP}_{\mathrm{i}}$ concentrations were determined with a commercial assay kit (Sigma) according to the directions of the manufacturer. Control values were subtracted from the values obtained by using complete assay mixtures. ATPdependent acetate kinase (EC 2.7.2.1) reactions in the direction of acetyl phosphate formation were examined by using the method of Bowman et al. (3), with potassium acetate added to a concentration of $50 \mathrm{mM}$ and sodium succinate (a positive effector in Escherichia coli [35]) added to a concentration of $10 \mathrm{mM}$. For each strain, a second assay mixture containing boiled cell-free extract was used as a blank for the spectrophotometric determination of acetyl hydroxamate by the method of Skarstedt and Silverstein (35). $\mathrm{PP}_{\mathrm{i}}$-dependent acetate kinase (EC 2.7.2.12) was determined similarly, except that the concentration of $\mathrm{MgCl}_{2}$ was reduced to 0.75 $\mathrm{mM}$ to prevent precipitation with $\mathrm{PP}_{\mathrm{i}}$. Alternatively, to circumvent potential inhibition by $\mathrm{PP}_{\mathrm{i}}$ of color formation in the hydroxylamine assay for acetyl phosphate in the $\mathrm{PP}_{\mathrm{i}}$ dependent acetate kinase reaction, the method of Reeves and Guthrie (25) was used. Sodium dithionite, which reportedly stimulates the reaction in Desulfotomaculum ruminis (15), was added to a concentration of $25 \mathrm{mM}$. Pyruvate kinase (EC 2.7.1.40) was assayed by using the method of Smart and Pritchard (36); PEP was added to a concentration of $4 \mathrm{mM}$. Glucose-6-phosphate dehydrogenase (EC 1.1.1.49) was assayed anaerobically by using the method described elsewhere (Petzel et al., in press).

\section{RESULTS AND DISCUSSION}

Weisburg and co-workers (Weisburg et al., submitted) used 16S rRNA analyses to determine that the walled bacteria which are phylogenetically related to the mollicutes can be divided into monophyletic subgroups. Clostridium innocuum clustered with Streptococcus pleomorphus, and Clostridium ramosum clustered with Lactobacillus catenaformis and Lactobacillus vitulinus. Erysipelothrix rhusiopathiae did not belong to either cluster, but Weisburg et al. (submitted) have reported that there were some data to suggest that Erysipelothrix rhusiopathiae is more closely related to the Clostridium innocuum-Streptococcus pleomorphus cluster than to the Clostridium ramosum-lactobacillus cluster.

The purpose of the present study was as follows: (i) to determine whether the walled bacteria that are related to the mollicutes possess $\mathrm{PP}_{\mathrm{i}}$-dependent enzymes as the mollicutes do, thereby providing a phenotypic indication of the phylogenetic relatedness of these organisms and (ii) to determine whether the distribution of $\mathrm{PP}_{\mathrm{i}}$-dependent enzymes among the six walled bacteria which we studied complements the phylogenetic subdivisions of this group proposed by Weisburg et al. (submitted).

Functional and structural patterns of various enzymes have been used as the bases for taxonomic and phylogenetic 
classifications $(4,11,39)$. Weitzman (39) reported that regulatory and size characteristics of citrate synthase and succinate thiokinase can be used to separate gram-positive from gram-negative bacteria and also aerobic gram-negative bacteria from facultative anaerobes. Jensen and co-workers (4, 11) have performed phylogenetic studies of various groups of bacteria and their pathways for aromatic amino acid biosynthesis by studying differences in isozymes, cofactor specificities, allosteric controls, and alternative biochemical steps; these authors determined that phylogenetic clusters of bacteria share distinctive biochemical features. However, these workers stressed that any conclusions about the phylogeny or evolution of organisms or their biochemical pathways must be made within the framework of phylogenetic relationships previously determined by other established methods, such as rRNA analysis (11).

The data reported in this paper represent enzyme activities determined in vitro (i.e., from cell extracts); thus, extrapolations to quantitative conclusions about conditions in vivo would be tenuous. When we could not detect an enzyme activity, when possible, enzyme from a commercial source or a known-positive organism was added to the putatively inactive cell-free extract to determine the efficacy of the assay system. Previous studies have demonstrated that, except for well-documented, isolated cases (see reference 1 for an example), most enzymes of carbohydrate metabolism (including $\mathrm{PP}_{\mathrm{i}}$-dependent enzymes) are not $\mathrm{O}_{2}$ labile (6, 12, 26; Petzel et al., in press).

PFK. Among the walled bacteria, $\mathrm{PP}_{\mathrm{i}}$-PFK has previously been detected in a Clostridium sp. isolated from a cockroach gut (6), Propionibacterium freundenreichii and Propionibacterium acidipropionici ("Propionibacterium arabinosum") (21, 43, 45), some Bacteroides spp. (26), and Deleya spp. (33). Among the bacteria belonging to the class Mollicutes, PP $_{\mathrm{i}}$-PFK has been detected in Acholeplasma spp., but the PFK activities among Mycoplasma spp. and Spiroplasma spp., when present, are active with ATP but not $\operatorname{PP}_{\mathrm{i}}(7,22$, 23; M. H. V. Lake-Bullock, W. T. Blevins, S. K. McGlynn, and T. L. Rhoads, Abstr. Annu. Meet. Am. Soc. Microbiol. 1989, G-39, p. 155). In the anaerobic mollicutes, Asteroleplasma anaerobium $161^{\mathrm{T}}$ has ATP-PFK activity, and Anaeroplasma intermedium 5LA has $\mathrm{PP}_{\mathrm{i}}$-PFK activity (Petzel et al., in press); $\mathrm{PP}_{\mathrm{i}}$-PFK activity has also been detected in Anaeroplasma bactoclasticum $\mathrm{JR}^{\mathrm{T}}$, the type species of the genus (Petzel, unpublished results).

In the present study, Clostridium innocuum and Streptococcus pleomorphus (one of the clusters within the group of six bacteria) had $\mathrm{PP}_{\mathrm{i}}-\mathrm{PFK}$ activities in both the forward and reverse directions (Table 1 ). However, Clostridium ramosum, Lactobacillus catenaformis, and Lactobacillus vitulinus (another cluster) had only ATP-PFK activity (Table 1). Erysipelothrix rhusiopathiae had $\mathrm{PP}_{\mathrm{i}}-\mathrm{PFK}$ activity (Table 1), in agreement with the phylogenetic evidence of Weisburg et al. (submitted) that suggests that Erysipelothrix rhusiopathiae is more closely allied with the Clostridium innocuum cluster than with the Clostridium ramosum cluster.

Parenthetically, PFK activities were sometimes detected in the two strains of Clostridium innocuum, in Streptococcus pleomorphus, and in the two strains of Anaeroplasma intermedium when ATP was substituted for $\mathrm{PP}_{\mathrm{i}}$; this was not observed with Erysipelothrix rhusiopathiae. This ATPlinked PFK activity was not detected in all extract preparations of these organisms. Indeed, in a previous study, we did not detect ATP-linked activity in Anaeroplasma intermedium 5LA (Petzel et al., in press). In the present study, the ATP-linked activities were always less than the PP $_{\mathrm{i}}$-PFK
TABLE 1. PFK activities in walled bacteria phylogenetically related to members of the class Mollicutes and in anaerobic mollicutes

\begin{tabular}{|c|c|c|c|}
\hline \multirow{3}{*}{ Species $^{a}$} & \multicolumn{3}{|c|}{$\begin{array}{c}\text { PFK activity } \\
(\mathrm{nmol} / \mathrm{min} \text { per } \mathrm{mg})^{b}\end{array}$} \\
\hline & \multicolumn{2}{|c|}{$\mathrm{PP}_{\mathrm{i}}$-PFK } & \multirow[b]{2}{*}{ ATP-PFK } \\
\hline & $\begin{array}{l}\text { Forward } \\
\text { reaction }\end{array}$ & $\begin{array}{l}\text { Reverse } \\
\text { reaction }\end{array}$ & \\
\hline Clostridium innocuum ATCC $14501^{\mathrm{T}}$ & 610 & 620 & $0.41^{c}$ \\
\hline Clostridium innocuum 7207 & 260 & 340 & $14^{c}$ \\
\hline $\begin{array}{l}\text { Streptococcus pleomorphus ATCC } \\
29734^{\mathrm{T}}\end{array}$ & 650 & 740 & $14^{c}$ \\
\hline Clostridium ramosum 8546 & $\mathrm{NA}^{d}$ & NA & 68 \\
\hline $\begin{array}{l}\text { Lactobacillus catenaformis ATCC } \\
25536^{\mathrm{T}}\end{array}$ & NA & NA & 200 \\
\hline Lactobacillus vitulinus ATCC $27783^{\mathrm{T}}$ & NA & NA & 53 \\
\hline Erysipelothrix rhusiopathiae AVR-9 & 920 & 960 & NA \\
\hline Anaeroplasma intermedium 5LA & 380 & 190 & $39^{c}$ \\
\hline Anaeroplasma intermedium $7 \mathrm{LA}^{\mathrm{T}}$ & 120 & 80 & $4.2^{c}$ \\
\hline Asteroleplasma anaerobium $161^{\mathrm{T}}$ & NA & NA & 37 \\
\hline
\end{tabular}

${ }^{a}$ Species are grouped according to the phylogenetic subdivisions determined by Weisburg et al. (submitted).

${ }^{b}$ Data are the means of determinations from two batches of cells, except for Anaeroplasma intermedium $7 \mathrm{LA}^{\mathrm{T}}$ and Asteroleplasma anaerobium $16 \mathrm{1}^{\mathrm{T}}$ (single batches of these strains were tested) (see below). See text for details of assays.

c ATP-linked PFK activities in Clostridium innocuum ATCC $14501^{\mathrm{T}}$ and 7207 , Streptococcus pleomorphus ATCC $29734^{\mathrm{T}}$, and Anaeroplasma intermedium $7 \mathrm{LA}^{\mathrm{T}}$ were detected in only one extract preparation; in Anaeroplasma intermedium 5LA, ATP-linked PFK activity was detected in four preparations. See text.

${ }^{d}$ NA, No activity detected.

activities in these species (Table 1). Among the other microorganisms that have $\mathrm{PP}_{\mathrm{i}}$-PFK activities, Clostridium $\mathrm{sp.} \mathrm{(6),}$ Euglena gracilis (19), Propionibacterium spp. (21, 45), and Bacteroides spp. (26) have been reported to also have ATP-PFK activities, but Deleya spp. has only $\mathrm{PP}_{\mathrm{i}}$-PFK activity (33). Reeves (24) initially reported that Entamoeba

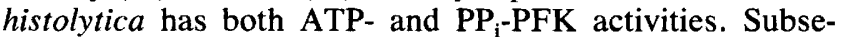
quent investigations revealed that the seeming ATP-PFK activity resulted from the generation of $\mathrm{PP}_{\mathrm{i}}$ from ATP by the glycogen-forming apparatus; strong centrifugal forces removed the ATP-linked activity from the extracts (24). Roberton and Glucina (26) reported that less ATP-PFK activity was detected in extracts of Bacteroides spp. subjected to a centrifugal force of $190,000 \times g$ for $1 \mathrm{~h}$ than in extracts subjected to a centrifugal force of $27,000 \times g$ for $20 \mathrm{~min}$. The ATP-PFK activity of Propionibacterium freundenreichii was stable to a centrifugal force of $124,000 \times g$ for $1 \mathrm{~h}$ (21). In the present study, we routinely used a centrifugal force of $230,000 \times g_{\max }$ for $1 \mathrm{~h}$. We did not observe any marked reduction in ATP-linked activity in lysates of Anaeroplasma intermedium 5LA clarified by a centrifugal force of 330,000 $\times g_{\max }$ for $120 \mathrm{~min}$ compared with lysates clarified at 27,000 $\times g_{\max }$ for 20 min (data not shown).

To ensure that this ostensive ATP-PFK activity was not caused by contamination of assay components with $\mathrm{PP}_{\mathrm{i}}(24)$, we performed the investigations described below. Using a $\mathrm{PP}_{\mathrm{i}}$ assay kit (Sigma), we did not detect $\mathrm{PP}_{\mathrm{i}}$ in either the ATP stock solutions or in cell-free extracts of Anaeroplasma intermedium 5LA. PP $-\mathrm{PFK}$ purified from Propionibacterium freundenreichii (Sigma) was not active with our ATP 
TABLE 2. PPDK activities in walled bacteria phylogenetically related to members of the class Mollicutes and in anaerobic mollicutes

\begin{tabular}{|c|c|c|}
\hline \multirow{2}{*}{ Species $^{a}$} & \multicolumn{2}{|c|}{$\begin{array}{c}\text { PPDK activity } \\
(\mathrm{nmol} / \mathrm{min} \text { per } \mathrm{mg})^{b}\end{array}$} \\
\hline & $\begin{array}{l}\text { Assay for } \\
\text { ATP }\end{array}$ & $\begin{array}{l}\text { Assay for } \\
\text { pyruvate }\end{array}$ \\
\hline Clostridium innocuum ATCC $14501^{\mathrm{T}}$ & 9.7 & 12 \\
\hline Clostridium innocuum 7207 & 13 & 12 \\
\hline Streptococcus pleomorphus ATCC $29734^{\mathrm{T}}$ & 30 & 30 \\
\hline Clostridium ramosum 8546 & 67 & 94 \\
\hline Lactobacillus catenaformis ATCC $25536^{\mathrm{T}}$ & 17 & 110 \\
\hline Lactobacillus vitulinus ATCC $27783^{\mathrm{T}}$ & 23 & 31 \\
\hline Erysipelothrix rhusiopathiae AVR-9 & $\mathbf{N A}^{c}$ & NA \\
\hline Anaeroplasma intermedium 5LA & NA & NA \\
\hline Anaeroplasma intermedium $7 \mathrm{LA}^{\mathrm{T}}$ & NA & NA \\
\hline Asteroleplasma anaerobium $161^{\mathrm{T}}$ & 110 & 340 \\
\hline
\end{tabular}

${ }^{a}$ Species are grouped according to the phylogenetic subdivisions determined by Weisburg et al. (submitted).

${ }^{b}$ Data are the means of determinations from two batches of cells (except for Anaeroplasma intermedium $7 \mathrm{LA} \mathrm{A}^{\mathrm{T}}$ and Asteroleplasma anaerobium $161^{\mathrm{T}}$; single batches of these strains were tested). See text for details of assays.

${ }^{c}$ NA, No activity detected.

solutions. To determine whether extracts of Anaeroplasma intermedium 5LA could generate $\mathrm{PP}_{\mathrm{i}}$ from ATP, we assayed for the appearance of $\mathrm{PP}_{\mathrm{i}}$ in ATP-PFK reaction mixtures containing all of the components except fructose 6-phosphate; no $\mathrm{PP}_{\mathrm{i}}$ was detected. (Conversely, extracts of Anaeroplasma intermedium 5LA and Clostridium innocuum 7207 did not generate detectable amounts of ATP from $\mathrm{PP}_{\mathrm{i}}$.) Furthermore, the inclusion of $5 \mathrm{U}$ of yeast inorganic pyrophosphorylase per $\mathrm{ml}$ of PFK assay mixture diminished $\mathrm{PP}_{\mathrm{i}}$-dependent activities, but not ATP-dependent activities, in Anaeroplasma intermedium 5LA and Clostridium innocuum 7207 (data not shown). These observations suggest the presence of bona fide ATP-PFK in Clostridium innocuum, Streptococcus pleomorphus, and Anaeroplasma intermedium; purification of the ATP-dependent activity from the $\mathrm{PP}_{\mathrm{i}}$-dependent activity would provide definite proof. The observations of the putative ATP-PFK aside, the occurrence of PP $\mathrm{i}_{\mathrm{i}}$-PFK among some of the mollicutes and three of their six walled relatives is indicative of the phylogenetic relatedness of these organisms.

The occurrence of $\mathrm{PP}_{\mathrm{i}}$-PFK in Acholeplasma spp. $(7,23)$ and in Anaeroplasma spp. (Petzel et al., in press; this study) and the absence of PP - PFK in other mollicutes (including Asteroleplasma anaerobium $\left.161^{\mathrm{T}}\right)(7$; Petzel et al., in press) correlate with the subgroups of mollicutes determined by Weisburg et al. (submitted) when 16S rRNA sequence analyses were used. These authors reported that Acholeplasma laidlawii and Acholeplasma modicum grouped with Anaeroplasma spp., to the exclusion of the other mollicutes.

PPDK and pyruvate kinase. PPDK converts PEP, adenosine 5'-monophosphate (AMP), and $\mathrm{PP}_{\mathrm{i}}$ to pyruvate, ATP, and orthophosphate. This enzyme has previously been reported in Propionibacterium freundenreichii, Propionibacterium acidipropionici, Clostridium symbiosum ("Bacteroides symbiosus") some Acetobacter spp., the clostridium isolated from a cockroach gut, and three anoxygenic photosynthetic bacteria $(6,8,9,43,45)$. Among the mollicutes, PPDK has been detected in Asteroleplasma anaerobium (Petzel et
TABLE 3. Effects of three potential allosteric activators on pyruvate kinase activities in walled phylogenetic relatives of members of the class Mollicutes and in anaerobic mollicutes

\begin{tabular}{|c|c|c|c|c|}
\hline \multirow{2}{*}{ Species $^{a}$} & \multicolumn{4}{|c|}{$\begin{array}{l}\text { Pyruvate kinase activity } \\
\left(\mathrm{nmol} / \mathrm{min} \text { per } \mathrm{mg} \text { ) } \text { with }^{b} \text { : }\right.\end{array}$} \\
\hline & $\begin{array}{c}\text { No } \\
\text { additives }\end{array}$ & $\begin{array}{c}0.5 \mathrm{mM} \\
\text { Fru-1,6-P }\end{array}$ & $\begin{array}{c}1.5 \mathrm{mM} \\
\text { AMP }\end{array}$ & $\begin{array}{l}0.5 \mathrm{mM} \\
\text { Glc-6-P }\end{array}$ \\
\hline $\begin{array}{l}\text { Clostridium innocuum } \\
\text { ATCC } 14501^{\mathrm{T}}\end{array}$ & 7.0 & 10 & 49 & 130 \\
\hline Clostridium innocuum 7207 & 14 & 31 & 43 & 280 \\
\hline $\begin{array}{l}\text { Streptococcus pleomorphus } \\
\quad \text { ATCC } 29734^{\mathrm{T}}\end{array}$ & 1.3 & 0.52 & $\mathbf{N A}^{c}$ & 4.4 \\
\hline Clostridium ramosum 8546 & 20 & 19 & 200 & 540 \\
\hline $\begin{array}{l}\text { Lactobacillus catenaformis } \\
\text { ATCC } 25536^{\mathrm{T}}\end{array}$ & NA & NA & 260 & NA \\
\hline $\begin{array}{l}\text { Lactobacillus vitulinus } \\
\text { ATCC } 27783^{\mathrm{T}}\end{array}$ & 120 & 320 & 810 & 660 \\
\hline $\begin{array}{l}\text { Erysipelothriz rhusiopathiae } \\
\text { AVR-9 }\end{array}$ & NA & NA & NA & NA \\
\hline $\begin{array}{l}\text { Anaeroplasma intermedium } \\
\text { 5LA }\end{array}$ & 170 & 160 & 170 & 180 \\
\hline $\begin{array}{l}\text { Anaeroplasma intermedium } \\
7 \mathrm{LA}^{\mathrm{T}}\end{array}$ & 81 & 85 & 90 & 80 \\
\hline $\begin{array}{l}\text { Asteroleplasma anaerobium } \\
161^{\mathrm{T}}\end{array}$ & NA & NA & NA & NA \\
\hline
\end{tabular}

${ }^{a}$ Species are grouped according to the phylogenetic subdivisions determined by Weisburg et al. (submitted).

${ }^{b}$ Data are the means of determinations from two batches of cells (except Anaeroplasma intermedium $7 \mathrm{LA}^{\mathrm{T}}$ and Asteroleplasma anaerobium $161^{\mathrm{T}}$; single batches of these strains were tested). See text for details of assay.

$c$ NA, No activity detected.

al., in press) but not in any of the 10 other mollicutes examined (17).

In the present study, PPDK activity was detected in Clostridium innocuum, Clostridium ramosum, Lactobacillus catenaformis, Lactobacillus vitulinus, Streptococcus pleomorphus, and Asteroleplasma anaerobium, but not in Erysipelothrix rhusiopathiae or Anaeroplasma intermedium (Table 2). The activities were detected by assaying for both the conversion of PEP to pyruvate and the conversion of AMP to ATP. The fact that Asteroleplasma anaerobium is the only mollicute that has been reported to possess PPDK activity is phenotypic evidence that supports the unique phylogenetic status of this organism among the mollicutes (Weisburg et al., submitted). No conclusions about the specific relationship (if indeed any exists) between Asteroleplasma anaerobium and the walled relatives can be made on the basis of the present information concerning PPDK.

All of the walled relatives of the mollicutes except Erysipelothrix rhusiopathiae had pyruvate kinase activity, a second enzyme activity that interconverts PEP and pyruvate; the activity for Streptococcus pleomorphus was low and variable (Table 3 ). In previous studies, the pyruvate kinases of Mycoplasma spp., Acholeplasma spp., Ureaplasma urealyticum, and Anaeroplasma intermedium 5LA $(5,17$; Petzel et al., in press) were detected in the absence of allosteric activators. In contrast, the pyruvate kinase activities in four of five walled bacteria determined in the present study to possess the enzyme were significantly increased by one or more activators (Table 3). Fructose 1,6-bisphosphate (Fru-1,6- $\mathrm{P}_{2}$ ) had only moderate effects or no effect on the 
pyruvate kinase activities of Clostridium innocuum, Streptococcus pleomorphus, and Clostridium ramosum; AMP and glucose 6-phosphate (Glc-6-P) were more effective.

Fru-1,6- $\mathrm{P}_{2}$ activates pyruvate kinases in a wide variety of bacteria $(32,36,46)$; fewer bacteria have pyruvate kinases activated by Glc-6-P but not Fru-1,6- $\mathrm{P}_{2}(36,46)$. Yamada and Carlsson (46) suggested that organisms that have both the Embden-Meyerhof-Parnas and pentose phosphate pathways for the degradation of glucose may use Fru-1,6- $\mathrm{P}_{2}$ as an activator for pyruvate kinase because Glc-6-P is the branch point between the two pathways. However, organisms that lack the oxidative portion of the pentose phosphate pathway may use Glc-6-P as the primary activator for pyruvate kinase. We did not detect Glc-6-P dehydrogenase (the first enzyme in the oxidative portion of the pentose phosphate pathway) in cell-free extract preparations of any of the bacteria except Streptococcus pleomorphus $(4.9 \mathrm{nmol} / \mathrm{min}$ per mg).

In the two lactobacilli, AMP was the best activator of pyruvate kinases; indeed, no activity was observed in extracts of Lactobacillus catenaformis in the absence of AMP (Table 3). Thus, the two lactobacilli differed from the third member of their phylogenetic subgroup, Clostridium ramosum. Weisburg et al. (submitted) have reported that although the lactobacilli cluster with Clostridium ramosum, they are more closely related to each other than to Clostridium ramosum.

The pyruvate kinase activity of Anaeroplasma intermedium was not significantly increased by any of the three effectors (Table 3). If the absence of allosteric activation of pyruvate kinase is confirmed for mollicutes in general, this would indicate that allosteric regulation of this enzyme arose in the walled relatives after the wall-less organism(s) diverged from the walled progenitor(s). The absence in Asteroleplasma anaerobium of pyruvate kinase activity, an enzyme activity detected in all other mollicute species examined, is further phenotypic evidence of the distinct phylogenetic status of this organism among the members of the class Mollicutes.

We could not detect either PPDK activity or pyruvate kinase activity in extracts of Erysipelothrix rhusiopathiae (Tables 2 and 3). The addition of Glc-6-P, Fru-1,6- $\mathrm{P}_{2}$, or AMP had no effect. Robertson and McCullough (27) reported that Erysipelothrix rhusiopathiae degrades glucose via the Embden-Meyerhof-Parnas pathway, based on the distribution of ${ }^{14} \mathrm{C}$ among products of $\left[{ }^{14} \mathrm{C}\right]$ glucose degradation. In the present study, the absence of detectable PPDK or pyruvate kinase activity in Erysipelothrix rhusiopathiae AVR-9 indicates either that our methods were not suitable for detecting these enzymes in this organism or that the avirulent vaccine strain used in the present study differed from strain S-192, which was used by Robertson and McCullough (27).

PEP carboxytransphosphorylase. PEP carboxytransphosphorylase occurs in Propionibacterium freundenreichii, Propionibacterium acidipropionici, some Rhodopseudomonas spp., Brevibacterium ammoniagenes ("Corynebacterium ammoniagenes"), and the clostridium isolated from a cockroach gut $(6,43-45)$. Acholeplasma laidlawii has been reported to possess PEP carboxytransphosphorylase activity (38; K. D. Beaman and J. D. Pollack, Yale J. Biol. Med. 57:897, 1984), but more recently, workers from the same laboratory have not been able to confirm this activity (17). In the present study, PEP carboxytransphosphorylase activities were detected by two methods in Clostridium innocuum, Streptococcus pleomorphus, and Clostridium ramosum (Ta-
TABLE 4. PEP carboxytransphosphorylase activities in walled bacteria phylogenetically related to members of the class Mollicutes and in anaerobic mollicutes

\begin{tabular}{|c|c|c|}
\hline \multirow{2}{*}{ Species $^{a}$} & \multicolumn{2}{|c|}{$\begin{array}{l}\text { PEP carboxytrans- } \\
\text { phosphorylase activity } \\
\text { (nmol/min per mg) }^{b}\end{array}$} \\
\hline & $\begin{array}{l}\text { Assay for } \\
\text { oxaloacetate }\end{array}$ & $\begin{array}{c}\text { Assay for } \\
\text { PP }_{i}\end{array}$ \\
\hline Clostridium innocuum ATCC $14501^{\mathrm{T}}$ & 5.5 & 22 \\
\hline Clostridium innocuum 7207 & 22 & 81 \\
\hline Streptococcus pleomorphus ATCC $29734^{\mathrm{T}}$ & 27 & 25 \\
\hline Clostridium ramosum 8546 & 8.2 & 5.5 \\
\hline Lactobacillus catenaformis ATCC $25536^{\mathrm{T}}$ & $\mathrm{NA}^{c}$ & 2.5 \\
\hline Lactobacillus vitulinus ATCC $27783^{\mathrm{T}}$ & NA & 0.71 \\
\hline Erysipelothrix rhusiopathiae AVR-9 & NA & NA \\
\hline Anaeroplasma intermedium 5LA & NA & 7.4 \\
\hline Anaeroplasma intermedium $7 \mathrm{LA}^{\mathrm{T}}$ & NA & 5.7 \\
\hline Asteroleplasma anaerobium $161^{\mathrm{T}}$ & NA & NA \\
\hline \multicolumn{3}{|c|}{$\begin{array}{l}{ }^{a} \text { Species are grouped according to the phylogenetic subdivisions deter- } \\
\text { mined by Weisburg et al. (submitted). } \\
b \text { Data are the means of determinations from two batches of cells (except for } \\
\text { Anaeroplasma intermedium } 7 \mathrm{LA}^{\mathrm{T}} \text { and Asteroleplasma anaerobium } 161^{\mathrm{T}} \text {; } \\
\text { single batches of these strains were assayed twice). See text for details of } \\
\text { assays. } \\
{ }^{c} \mathrm{NA} \text {, No activity detected. }\end{array}$} \\
\hline
\end{tabular}

ble 4). Low levels of the enzyme were detected in Lactobacillus catenaformis, Lactobacillus vitulinus, and the two strains of Anaeroplasma intermedium by the method which detected $\mathrm{PP}_{\mathrm{i}}$, but not by the method which detected oxaloacetate (Table 4). No PEP carboxytransphosphorylase activity was detected in Erysipelothrix rhusiopathiae or Asteroleplasma anaerobium (Table 4). Thus, PEP carboxytransphosphorylase is an additional $\mathrm{PP}_{\mathrm{i}}$-dependent enzyme that is possessed by some of the walled relatives of the members of the class Mollicutes.

Acetate kinase. $\mathrm{PP}_{\mathrm{i}}$-dependent acetate kinase activities have been reported in Entamoeba histolytica (25) and in gram-negative sulfate-reducing anaerobes $(15,43)$. We did not detect $\mathrm{PP}_{\mathrm{i}}$-dependent acetate kinase activity in the direction of acetyl phosphate in any of the organisms which we examined; duplicate extracts of all organisms were tested by the modified method of Bowman et al. (3), and single extracts of Clostridium innocuum ATCC $14501^{\mathrm{T}}$, Clostridium ramosum, Erysipelothrix rhusiopathiae, Lactobacillus catenaformis, and Streptococcus pleomorphus were tested by using the method of Reeves and Guthrie (25). However, all of the species had activity for ATP-dependent acetate kinase in the direction of acetyl phosphate, as follows (means of determinations, in micromoles per minute per milligram, from two batches of cells, except as noted): Clostridium innocuum ATCC 14501 ${ }^{\mathrm{T}}, 132$; Clostridium innocuum 7207, 355; Streptococcus pleomorphus, 228; Clostridium ramosum, 77.9; Lactobacillus catenaformis, 27.2; Lactobacillus vitulinus, 16.4; Erysipelothrix rhusiopathiae, 155; Anaeroplasma intermedium 5LA, 30.3; Anaeroplasma intermedium $7 \mathrm{LA}^{\mathrm{T}}$ (single batch), 10.2; and Asteroleplasma anaerobium (single batch), 424. (We did not attempt to determine ATP-dependent acetate kinase activity in the direction of acetate and ATP synthesis because of the high levels of adenylate kinase activity in extracts of Anaeroplasma intermedium 5LA and Asteroleplasma anaerobium $161^{\mathrm{T}}$. Adenylate kinase, which converts $2 \mathrm{~mol}$ of adenosine 
5 '-diphosphate to $1 \mathrm{~mol}$ of ATP and $1 \mathrm{~mol}$ of AMP, interfered with the assay for ATP production in the ATP-dependent acetate kinase reaction.) Muhlrad et al. (20) did not detect ATP-dependent acetate kinase activity in Anaeroplasma abactoclasticum 6-1 $1^{\mathrm{T}}$ or Anaeroplasma intermedium $7 \mathrm{LA}^{\mathrm{T}}$. These researchers used the hydroxylamine method to detect acetyl phosphate production $(20,35)$, the same method used in the present study $(3,35)$. Kotzé (13) reported that the hydroxylamine method is subject to interference by substances in the sample and that it does not give reproducible results, but other researchers have used this method in extensive kinetic analyses of acetate kinases from Veillonella alcalescens (3) and Escherichia coli (35). Robinson and co-workers $(28,29)$ reported that acetate is produced from starch by Anaeroplasma abactoclasticum $6-1^{\mathrm{T}}$ and Anaeroplasma intermedium $7 \mathrm{LA}^{\mathrm{T}}$ and 5LA. Thus, the correlation between the production of acetate from starch and the production of acetyl phosphate from acetate and ATP suggests that these strains do possess acetate kinases.

Phylogenetic implications. The possession of a $\mathrm{PP}_{\mathrm{i}}$-dependent enzyme(s) by any two given species does not, by itself, necessarily denote a phylogenetic relationship between those species. For example, the bacteria examined in the present study and Propionibacterium spp. have several $\mathrm{PP}_{\mathrm{i}}$-dependent enzymes in common, but the propionibacteria belong to a different subdivision of gram-positive eubacteria, as determined by rRNA analysis (40). However, given that the bacteria examined in the present study are phylogenetically related to the mollicutes, the occurrence of one or more $\mathrm{PP}_{\mathrm{i}}$-dependent enzymes in each of these bacteria (enzymes that occur in other organisms infrequently) is phenotypic evidence that supports the phylogenetic relationship between the mollicutes and their walled relatives. Two unrelated clostridia, Clostridium bifermentans and Clostridium butyricum, did not have detectable $\mathrm{PP}_{\mathrm{i}}$-PFK or PPDK activities (data not shown).

Among mollicutes, the following four $\mathrm{PP}_{\mathrm{i}}$-dependent enzymes have been reported: $P_{\mathrm{i}}$-PFK, PPDK, PEP carboxytransphosphorylase, and $\mathrm{PP}_{\mathrm{i}}$-dependent nucleoside kinase. $\mathrm{PP}_{\mathrm{i}}$-dependent nucleoside kinase has been found in all three orders of the class Mollicutes $(18,22)$, whereas the other three enzymes have been reported only among members of the orders Acholeplasmatales and Anaeroplasmatales (7, 17; Petzel et al., in press; this study). The occurrence of multiple $\mathrm{PP}_{\mathrm{i}}$-dependent enzymes among the members of the orders Acholeplasmatales and Anaeroplasmatales and the walled phylogenetic relatives and the reported lack of any $\mathrm{PP}_{\mathrm{i}}$-dependent enzymes besides $\mathrm{PP}_{\mathrm{i}}$-dependent nucleoside kinase among the members of the order Mycoplasmatales support the rRNA sequence analyses that suggest that the acholeplasmas and anaeroplasmas represent the first branch(es) from the walled group $(31,40)$.

The findings reported in this paper are phenotypic indicators of the phylogenetic relatedness of the mollicutes to certain walled bacteria. The distributions of these enzymes substantiate the subdivision of this phylogenetic group as determined by $16 \mathrm{~S}$ rRNA analyses. Characterization of these enzymes at the structural level (34) could help elucidate evolutionary lineages of the members of the class Mollicutes and their walled relatives.

\section{LITERATURE CITED}

1. Abbe, K., S. Takahashi, and T. Yamada. 1982. Involvement of oxygen-sensitive pyruvate formate-lyase in mixed-acid fermentation by Streptococcus mutans under strictly anaerobic conditions. J. Bacteriol. 152:175-182.
2. Beutler, H.-O., and M. Supp. 1983. Coenzymes, metabolites, and other biochemical reagents, p. 328-393. In H. U. Bergmeyer, J. Bergmeyer, and M. Grassl (ed.), Methods of enzymatic analysis, 3rd ed., vol. 2. Samples, reagents, assessment of results. Verlag Chemie, Deerfield Beach, Fla.

3. Bowman, C. M., R. O. Valdez, and J. S. Nishimura. 1976. Acetate kinase from Veillonella alcalescens. J. Biol. Chem. 251:3117-3121.

4. Byng, G. S., J. F. Kane, and R. A. Jensen. 1982. Diversity in the routing and regulation of complex biochemical pathways as indicators of microbial relatedness. Crit. Rev. Microbiol. 9: 227-252.

5. Cocks, B. G., F. A. Brake, A. Mitchell, and L. R. Finch. 1985. Enzymes of intermediary carbohydrate metabolism in Ureaplasma urealyticum and Mycoplasma mycoides subsp. mycoides. J. Gen. Microbiol. 131:2129-2135.

6. Cruden, D. L., W. E. Durbin, and A. J. Markovetz. 1983. Utilization of $\mathrm{PP}_{\mathrm{i}}$ as an energy source by a Clostridium sp. Appl. Environ. Microbiol. 46:1403-1408.

7. DeSantis, D., V. V. Tryon, and J. D. Pollack. 1989. Metabolism of mollicutes: the Embden-Meyerhof-Parnas pathway and the hexose monophosphate shunt. J. Gen. Microbiol. 135:683-691.

8. Ernst, S. M., R. J. A. Budde, and R. Chollet. 1986. Partial purification and characterization of pyruvate,orthophosphate dikinase from Rhodospirillum rubrum. J. Bacteriol. 165:483488.

9. Evans, H. J., and H. G. Wood. 1971. Purification and properties of pyruvate phosphate dikinase from propionic acid bacteria. Biochemistry 10:721-729.

10. Gadeau, A.-P., C. Mouches, and J. M. Bove. 1986. Probable insensitivity of mollicutes to rifampin and characterization of spiroplasmal DNA-dependent RNA polymerase. J. Bacteriol. 166:824-828.

11. Jensen, R. A. 1985 . Biochemical pathways in prokaryotes can be traced backward through evolutionary time. Mol. Biol. Evol. 2:92-108.

12. Joyner, A. E., Jr., and R. L. Baldwin. 1966. Enzymatic studies of pure cultures of rumen microorganisms. J. Bacteriol. 92: 1321-1330.

13. Kotzé, J. P. 1968. An enzymatic optical method for the determination of nanomole quantities of acetyl phosphate. J. S. Afr. Chem. Inst. 21:105-112.

14. Kulaev, I. S., and V. M. Vagabov. 1983. Polyphosphate metabolism in micro-organisms. Adv. Microb. Physiol. 24:83-171.

15. Liu, C.-L., and H. D. Peck, Jr. 1981. Comparative bioenergetics of sulfate reduction in Desulfovibrio and Desulfotomaculum spp. J. Bacteriol. 145:966-973.

16. Ludwig, W., M. Weizenegger, R. Kilpper-Bälz, and $K$. H. Schleifer. 1988. Phylogenetic relationships of anaerobic streptococci. Int. J. Syst. Bacteriol. 38:15-18.

17. Manolukas, J. T., M. F. Barile, D. K. F. Chandler, and J. D. Pollack. 1988. Presence of anaplerotic reactions and transamination, and the absence of the tricarboxylic acid cycle in mollicutes. J. Gen. Microbiol. 134:791-800.

18. McElwain, M. C., D. K. F. Chandler, M. F. Barile, T. F. Young, V. V. Tryon, J. W. Davis, Jr., J. P. Petzel, C.-J. Chang, M. V. Williams, and J. D. Pollack. 1988. Purine and pyrimidine metabolism in Mollicutes species. Int. J. Syst. Bacteriol. 38:417-423.

19. Miyatake, K., T. Enomoto, and S. Kitaoka. 1984. Detection and subcellular distribution of pyrophosphate: D-fructose 6-phosphate phosphotransferase (PFP) in Euglena gracilis. Agric. Biol. Chem. 48:2857-2859.

20. Muhlrad, A., I. Peleg, J. A. Robertson, I. M. Robinson, and I. Kahane. 1981. Acetate kinase activity in mycoplasmas. J. Bacteriol. 147:271-273.

21. O'Brien, W. E., S. Bowien, and H. G. Wood. 1975. Isolation and characterization of a pyrophosphate-dependent phosphofructokinase from Propionibacterium shermanii. J. Biol. Chem. 250:8690-8695.

22. Pollack, J. D., M. C. McElwain, D. DeSantis, J. Manolukas, J. G. Tully, C.-J. Chang, R. F. Whitcomb, K. J. Hackett, and M. V. Williams. 1989. Metabolism of members of the Spiroplasmataceae. Int. J. Syst. Bacteriol. 39:406-412. 
23. Pollack, J. D., and M. V. Williams. 1986. $\mathrm{PP}_{\mathrm{i}}$-dependent phosphofructotransferase (phosphofructokinase) activity in the mollicutes (mycoplasma) Acholeplasma laidlawii. J. Bacteriol. 165: 53-60.

24. Reeves, R. E. 1987. Metabolic energy supplied by $P P_{i}, p$. 255-259. In A. Torriani-Gorini, F. G. Rothman, S. Silver, A. Wright, and E. Yagil (ed.), Phosphate metabolism and cellular regulation in microorganisms. American Society for Microbiology, Washington, D.C.

25. Reeves, R. E., and J. D. Guthrie. 1975. Acetate kinase (pyrophosphate). A fourth pyrophosphate-dependent kinase from Entamoeba histolytica. Biochem. Biophys. Res. Commun. 66: 1389-1395.

26. Roberton, A. M., and P. G. Glucina. 1982. Fructose 6-phosphate phosphorylation in Bacteroides species. J. Bacteriol. 150:10561060 .

27. Robertson, D. C., and W. G. McCullough. 1968. Glucose catabolism of Erysipelothrix rhusiopathiae. J. Bacteriol. 95:21122116.

28. Robinson, I. M., and M. J. Allison. 1975. Transfer of Acholeplasma bactoclasticum Robinson and Hungate to the genus Anaeroplasma (Anaeroplasma bactoclasticum [Robinson and Hungate] comb.nov.): emended description of the species. Int. J. Syst. Bacteriol. 25:182-186.

29. Robinson, I. M., M. J. Allison, and P. A. Hartman. 1975. Anaeroplasma abactoclasticum gen.nov., sp.nov.: an obligately anaerobic mycoplasma from the rumen. Int. J. Syst. Bacteriol. 25:173-181.

30. Robinson, I. M., and E. A. Freundt. 1987. Proposal for an amended classification of anaerobic mollicutes. Int. J. Syst. Bacteriol. 37:78-81.

31. Rogers, M. J., J. Simmons, R. T. Walker, W. G. Weisburg, C. R. Woese, R. S. Tanner, I. M. Robinson, D. A. Stahl, G. Olsen, R. H. Leach, and J. Manilofi. 1985. Construction of the mycoplasma evolutionary tree from 5S rRNA sequence data. Proc. Natl. Acad. Sci. USA 82:1160-1164.

32. Sanwal, B. D. 1970. Allosteric controls of amphibolic pathways in bacteria. Bacteriol. Rev. 34:20-39.

33. Sawyer, M. H., P. Baumann, and L. Baumann. 1977. Pathways of D-fructose and D-glucose catabolism in marine species of Alcaligenes, Pseudomonas marina, and Alteromonas communis. Arch. Microbiol. 112:169-172.
34. Selander, R. K., D. A. Caugant, H. Ochman, J. M. Musser, M. N. Gilmour, and T. S. Whittam. 1986. Methods of multilocus enzyme electrophoresis for bacterial population genetics and systematics. Appl. Environ. Microbiol. 51:873-884.

35. Skarstedt, M. T., and E. Silverstein. 1976. Escherichia coli acetate kinase mechanism studied by net initial rate, equilibrium, and independent isotopic exchange kinetics. J. Biol. Chem. 251:6775-6783.

36. Smart, J. B., and G. G. Pritchard. 1979. Regulation of pyruvate kinase from Propionibacterium shermanii. Arch. Microbiol. 122:281-288.

37. Trautschold, I., W. Lamprecht, and G. Schweitzer. 1985. Adenosine 5'-triphosphate, UV-method with hexokinase and glucose-6-phosphate dehydrogenase, p. 346-357. In H. U. Bergmeyer, J. Bergmeyer, and M. Grassl (ed.), Methods of enzymatic analysis, 3rd ed., vol. 7. Metabolites 2. VCH Publishers, Deerfield Beach, Fla.

38. Tryon, V. V., and D. Pollack. 1984. Purine metabolism in Acholeplasma laidlawii $\mathrm{B}$ : novel $\mathrm{PP}_{\mathrm{i}}$-dependent nucleoside $\mathrm{ki}-$ nase activity. J. Bacteriol. 159:265-270.

39. Weitzman, P. D. J. 1980. Citrate synthase and succinate thiokinase in classification and identification. Appl. Bacteriol. Symp. Ser. 8:107-125.

40. Woese, C. R. 1987. Bacterial evolution. Microbiol. Rev. 51: 221-271.

41. Woese, C. R., J. Maniloff, and L. B. Zablen. 1980. Phylogenetic analysis of the mycoplasmas. Proc. Natl. Acad. Sci. USA 77:494-498.

42. Woese, C. R., E. Stackebrandt, and W. Ludwig. 1985. What are mycoplasmas: the relationship of tempo and mode in bacterial evolution. J. Mol. Evol. 21:305-316.

43. Wood, H. G. 1985. Inorganic pyrophosphate and polyphosphates as sources of energy. Curr. Top. Cell. Regul. 26:355-369.

44. Wood, H. G., J. J. Davis, and J. M. Willard. 1969. Phosphoenolpyruvate carboxytransphosphorylase from Propionibacterium shermanii. Methods Enzymol. 13:297-309.

45. Wood, H. G., and N. H. Goss. 1985. Phosphorylation enzymes of the propionic acid bacteria and the roles of ATP, inorganic pyrophosphate, and polyphosphates. Proc. Natl. Acad. Sci. USA 82:312-315.

46. Yamada, T., and J. Carlsson. 1975. Glucose-6-phosphate-dependent pyruvate kinase in Streptococcus mutans. J. Bacteriol. 124:562-563. 